\title{
Does the effect of studying abroad on labour income vary by graduates' social origin? Evidence from Germany
}

\author{
Nicolai Netz ${ }^{1} \cdot$ Michael Grüttner ${ }^{1}$ \\ Published online: 23 July 2020 \\ (C) The Author(s) 2020
}

\begin{abstract}
Studying abroad can positively influence students' personality development, transversal skills, and labour market outcomes. At the same time, students from a high social origin are more likely to study abroad than students from a low social origin. Against this background, recent research has suggested that international student mobility (ISM) may foster the reproduction of social inequality. However, this assumption has hardly been tested empirically. Drawing on social stratification theory, we first demonstrate that a scenario in which ISM increases social inequality (cumulative advantage) is as plausible as a scenario in which it decreases social inequality (compensatory levelling). We then address the sketched research gap by testing whether the effect of studying abroad on graduates' labour income varies across social groups in the German labour market. Using data from the 2005 DZHW Graduate Panel, we perform a propensity score matching and calculate random effects growth curve models to examine the role of ISM for the development of social inequality during the first 10 years of graduates' careers. In line with the scenario of cumulative advantage, our results suggest that graduates from a high social origin benefit more from ISM than graduates from a low social origin. Considering that students from a high social origin are also more likely to study abroad in the first place, we conclude that ISM tends to foster the reproduction of social inequality in the German labour market.
\end{abstract}

Keywords Study abroad $\cdot$ Labour income $\cdot$ Social inequality $\cdot$ Effect heterogeneity $\cdot$ Germany

Nicolai Netz

netz@dzhw.eu

Michael Grüttner

gruettner@dzhw.eu

1 German Centre for Higher Education Research and Science Studies (DZHW), Lange Laube 12, 30159 Hannover, Germany 


\section{Introduction}

Studying abroad can positively influence students' personality development (Zimmermann and Neyer 2013; Zimmermann et al. 2020), transversal skills (Pinto 2020; Roy et al. 2019; Sorrenti 2017), and labour market outcomes (Iriondo 2020; Jacob et al. 2019; Kratz and Netz 2018; Liwiński 2019a; Petzold 2020; Waibel et al. 2017, 2018). In this context, various scholars have pointed out that the likelihood of getting access to the possible benefits of studying abroad varies notably across student groups (for an overview, see Netz et al. 2020). In particular, recent research has amply demonstrated that students from a high social origin are more likely to study abroad than students from a low social origin (Di Pietro 2019; Hauschildt et al. 2018; Lingo 2019; Netz and Finger 2016; Salisbury et al. 2009; Wiers-Jenssen 2011). Against this background, it has also suggested that international student mobility (ISM ${ }^{1}$ ) may foster the reproduction of social inequality (Di Pietro 2019; Kratz and Netz 2018; Lingo 2019; Schnepf and Colagrossi 2020).

Importantly, this conclusion hinges on the assumption that students from a high social origin benefit from ISM at least to similar extents as students from a low social origin. Somewhat surprisingly, however, this assumption has hardly been tested empirically. We systematically address this research gap by asking the following research question: Does the effect of studying abroad on labour income vary by graduates' social origin in the German labour market?

By addressing this question, we intend to contribute to both research on social stratification and research on the effects of ISM. On the one hand, we do so by providing new empirical evidence on heterogeneous income effects of ISM, which has become an important educational option. On the other hand, we shed light on a methodological issue by showing that, for studying effect heterogeneity depending on social (dis)advantage, it matters whether scholars use manifest or latent constructs, that is, parents' education/professional status or the propensity to embark upon an educational option.

Drawing on social stratification theory, we proceed by demonstrating that a scenario in which ISM increases social inequality (due to individuals from a high social origin benefiting from cumulative advantage) is as plausible as a scenario in which it decreases social inequality (due to individuals from a low social origin benefiting from compensatory levelling). We then recapitulate the existing studies that examine labour market-related effects of ISM depending on the social origin. Thereafter, we present our data, variables, and methods. Using data from the 2005 DZHW Graduate Panel, we perform a propensity score matching (PSM) and calculate random effects (RE) growth curve models to examine the role of ISM for the development of social inequality during the first 10 years of graduates' careers. We conclude by highlighting the theoretical and practical implications of our results, the limitations of our study, and several ways forward for research.

\section{Theory}

Why should studying abroad influence graduates' income at all? A prominent answer refers to human capital theory: From this perspective, studying abroad can be considered an investment

\footnotetext{
${ }^{1}$ We use the terms studying abroad and international student mobility (ISM) synonymously. They refer to stays abroad that students complete during higher education, such as study periods, internships, language courses, or other study-related stays.
} 
in students' skills. For instance, it can help students improve their language competence and ability to adapt to new environments. Following human capital theory, such skills should increase students' productivity, and thus allow them to receive higher wages on the labour market (Messer and Wolter 2007; Wiers-Jenssen and Try 2005). From the perspective of signalling theory, studying abroad can also be interpreted as a strategy of students to show employers that they possess skills which are desirable on the labour market, for the acquisition of which they are willing to incur the costs of completing a stay abroad (Petzold 2017; Van Mol 2017). Additionally, segmentation theory contributes to the explanation of labour market effects of studying abroad: It accentuates that ISM experience may grant access to particularly prosperous labour market segments, and to employers which are particularly willing and able to remunerate ISM experience, such as large and internationally oriented firms (Kratz and Netz 2018; Wiers-Jenssen and Try 2005). Finally, job search theory implies that, by increasing the job search radius and by decreasing the costs of searching for jobs and of becoming spatially mobile, studying abroad increases the likelihood of later labour market mobility. Thereby, it should improve access to well-paid positions (Kratz and Netz 2018).

Now why should ISM foster the reproduction of social inequality? In this respect, it is important to conceptually differentiate two perspectives. While the first and so far prominent perspective highlights social differences regarding the chances of studying abroad (social selectivity), the second and so far sometimes overlooked perspective additionally underscores the possibility that graduates from different social origins may benefit from studying abroad to differing extents (effect heterogeneity).

Following social stratification theory, the amply demonstrated social selectivity in access to study abroad opportunities can be understood as the result of a sense of distinction, which should drive students from a high social origin to attempt to secure their (parents') advantageous position in society (Bourdieu 1984). Faced with decreasing possibilities to distinguish themselves vertically through higher education degrees in the context of the massive educational expansion of the past decades (Schofer and Meyer 2005), students from a high social origin should try to increasingly distinguish themselves horizontally within higher education (Lucas 2001). Strategies for distinction within higher education include not only the choice of prestigious higher education institutions (Schindler and Reimer 2011; Triventi 2013) and rewarding fields of study (Triventi et al. 2017; Van De Werfhorst et al. 2003) but also the completion of study-related stays abroad (Lörz et al. 2016). Students from a high social origin should have better opportunities to study abroad because of their more favourable endowment with economic, social, and cultural capital (for a detailed discussion, see Netz and Finger 2016). In summary, this perspective explains why students from a high social origin should be more likely to get access to the possible benefits of studying abroad.

The second perspective explains why the effects of studying abroad may be heterogeneous across graduates from different social origins. In this regard, two concepts from social stratification research suggest that two opposing scenarios are plausible.

On the one hand, graduates from a high social origin could benefit from a cumulative advantage accruing to them over their earlier life course (DiPrete and Eirich 2006). Related to the resources of their parents as well as the habitus and skills that they acquire during childhood and youth, students from a high social origin may be able to complete more prestigious stays abroad than students from a low social origin (Netz and Finger 2016). In turn, prestigious stays abroad may prove particularly valuable for access to well-paid positions and prosperous labour market segments. Moreover, individuals from a high social origin can often make better use of specific experiences and credentials to improve their position in the 
labour market (Laurison and Friedman 2016). Again in relation to their habitus and skills, and also to their more abundant social capital, it is thus plausible that graduates from a high social origin are particularly able to valorise ISM experience in application procedures, job interviews, and on-the-job negotiations. This could allow them to capitalise on this experience more strongly. If the sketched dynamics apply, ISM could increase social inequality in the labour market. $^{2}$

On the other hand, graduates from a low social origin could benefit from compensatory levelling (Schafer et al. 2013). In relation to their lower likelihood of acquiring language skills and other intercultural competences during their earlier life course (Kuhn 2016), graduates from a low social origin could experience a compensation process in terms of the aforementioned and other skills when studying abroad. The marginal utility of studying abroad could thus be higher for them than for students from a high social origin, who may have acquired such skills in large part already through family travels, school exchanges, and the choice of academically oriented schools (Brooks and Waters 2010; Gerhards and Hans 2013; Lörz et al. 2016). A further explanation could be that graduates from a low social origin are positively self-selected in terms of their benefit expectations: Possibly, they only decide to study abroad if they are very strongly convinced of the benefits of studying abroad (Waibel et al. 2018). Assuming that they have the predispositions allowing their eventual returns to match their initial expectations, this could also explain a scenario in which graduates from a low social origin benefit relatively more from studying abroad. In summary, it is thus equally possible that ISM decreases social inequality in the labour market.

In order to eventually answer the question of whether ISM increases or decreases social inequality, the perspective of social selectivity and the perspective of effect heterogeneity need to be discussed in conjunction. As elaborated above, previous research has amply demonstrated that ISM is socially selective. However, students from a low social origin also study abroad to a notable extent (Hauschildt et al. 2018). Unlike in a situation in which only very few students from a low social origin study abroad, possible effect heterogeneity in the labour market outcomes of studying abroad can thus - at least theoretically - have a substantial bearing on how ISM influences social inequality. We therefore consider it reasonable to direct more attention to whether these effects are heterogeneous or not.

Although the different mechanisms sketched above can be at play simultaneously, we suggest that cumulative advantage is of more relevance if we find that graduates from high social origin profit more from studying abroad. On the other hand, if we find that graduates from low social origin profit more, we will conclude that compensatory levelling predominates.

\section{Previous research and research gap}

To the best of our knowledge, studies on labour market-related outcomes of ISM that differentiate by graduates' social origin are scarce at present. Existing empirical evidence on this issue tends to result from robustness checks rather than from comprehensive theory-guided

\footnotetext{
${ }^{2}$ Methodologically, the first dynamic (prestigious stays abroad) constitutes an example of a treatment heterogeneity. In contrast, the second dynamic may imply both a treatment heterogeneity and a moderated treatment effect, that is, a varying effect of the same or a very similar treatment by graduates' social origin. While this differentiation is negligible for our analysis, it would be an issue worth exploring in future research.
} 
analyses of heterogeneous effects of ISM depending on the social origin. The existing studies either use an instrumental variable (IV) approach or propensity score matching (PSM) to tackle estimation bias resulting from self-selection into ISM. ${ }^{3}$

Using an IV approach, Sorrenti (2017) examines the effect of EU-funded stays abroad (reference category: either no stay or a self-organised stay abroad) on the self-reported proficiency in career-relevant foreign languages (English, French, German, and Spanish) of graduates from Italian higher education institutions. As a robustness check, he presents an analysis differentiating between graduates from a high socio-economic background and from lower socio-economic backgrounds based on the parents' occupational status. He finds that "coefficients for [individuals] from more disadvantaged backgrounds are considerably larger than the coefficients for individuals from the high economic background. The case of Spanish remains an exception to the general rule" (p. 153).

Di Pietro (2015) also uses an IV approach to examine whether participation in an international exchange programme affects the employment likelihood of graduates from Italian universities at three years after graduation. In sensitivity analyses, he examines whether this effect differs between graduates from advantaged backgrounds (at least one parent with a higher education degree), graduates from disadvantaged backgrounds (at least one parent with lower or upper secondary education), and graduates from very disadvantaged backgrounds (parents have at most completed primary education). He finds a substantial and significantly positive effect for graduates from disadvantaged backgrounds and a slightly lower positive but insignificant effect for graduates from advantaged backgrounds. For graduates from very disadvantaged backgrounds, in contrast, he finds a negative but statistically insignificant effect, suggesting that "graduates from very disadvantaged backgrounds who decide to study abroad may not have a sufficient cultural preparation that enables them to fully take advantage of the employment-related benefits of an international educational experience" (p. 239).

Based on a PSM, Liwiński (2019b) examines whether studying abroad for at least one semester influences the employment likelihood during the early career of residents in Poland who have graduated from Polish higher education institutions. To study effect heterogeneity by the social origin, he compares graduates with at least one parent with a university degree to graduates with parents who hold at most a secondary education degree. Due to low case numbers, he omits graduates whose parents have not obtained a secondary education degree. His results "clearly show that studying abroad has a strong positive impact on the employability of the first group only - that is, respondents with at least one parent with a university degree" (p. 416).

Waibel et al. (2018) also use PSM to determine whether a stay abroad of at least one month influences the occupational status of residents in Germany at three years after graduating from higher education. Based on a comparison of the estimated average treatment effect on the treated (ATT) and the estimated average treatment effect on the controls (ATC), they find that "individuals with the lowest propensity to study abroad (those with the least economic, social,

\footnotetext{
3 The IV approach estimates a causal effect through a variable (instrument) that strongly predicts the treatment of interest, but is not correlated to the outcome of interest other than through the treatment. It can theoretically deal with selection into ISM based on unobserved characteristics. However, it is often difficult to determine in practice whether an instrument fulfills the above-mentioned requirements. PSM, in contrast, estimates a causal effect by comparing individuals with and without a treatment of interest who are identical or similar regarding variables that influence both the treatment and the outcome of interest. It can substantially reduce estimation bias by precisely modelling the process of selection into ISM based on observed characteristics, but it cannot deal with selection into ISM based on unobserved characteristics (for details, see Morgan and Winship 2014, and the methods section).
} 
and cultural resources) are the most likely to benefit from studying abroad in occupational terms" (p. 58). They conclude that "it is therefore unlikely that studying abroad is substantially related to social inequality in society" (p. 58). ${ }^{4}$

In summary, graduates in Italy seem to benefit most in terms of foreign language proficiency if they stem from lower economic backgrounds. Regarding the likelihood of employment, studying abroad seems to be most beneficial for graduates from an intermediate to high educational background in Italy. Evidence from Poland suggests that studying abroad is most beneficial regarding the employment likelihood for graduates from a high educational background. In Germany, those with a lower propensity to study abroad seem to experience a stronger positive effect on their later occupational status.

At first sight, these findings might appear to be contradictory. However, we suggest that they may well be reconcilable: First, existing studies have used different measures of ISM and of the social origin. Also, they have examined different labour market-related outcomes in different countries. The two Italian studies (Di Pietro 2015; Sorrenti 2017), on their part, might have come to similar results if they had used the same measures to operationalise the social origin. Second, as elaborated in the theory section, it could be promising to conceptually distinguish differential skill acquisition and differential valorisation of the acquired skills in the labour market. From this perspective, it is possible that graduates from a lower social origin benefit most in terms of skill acquisition but not necessarily in terms of their labour market outcomes. Third, it matters whether effect heterogeneity is studied using manifest constructs of social (dis)advantage, such as parents' education or professional status, or using latent constructs such as the propensity to study abroad (for an elaborate discussion of the latter approach, see Brand and Xie 2010).

To conclude, both research on social stratification and research on the effects of ISM would benefit from an in-depth analysis of the role of ISM for the development of social inequality. Focusing on the German labour market, we intend to provide such an analysis by examining how the effect of studying abroad on labour income varies depending on graduates' social origin as well as their propensity to study abroad.

The goal of our analysis is thus to determine whether ISM increases social inequality in Germany, and to assess whether the observed patterns are more congruent with the scenario of cumulative advantage or with the scenario of compensatory levelling. However, it is beyond the scope of our analysis to additionally examine the mechanisms explaining the outcomes we observe. In the theory section and the discussion, we still present several hypotheses on why ISM could either increase or decrease social inequality. We hope that these hypotheses will spur further research in the field.

\section{Data and sample restrictions}

To address the sketched research gap, we use data from the Graduate Panel of the German Centre for Higher Education Research and Science Studies (DZHW). Using stratified cluster

\footnotetext{
${ }^{4}$ Together with Di Pietro (2015), Waibel et al. (2018) present the most advanced discussion of effect heterogeneity in the returns to ISM. However, their conclusion is based on a mere comparison of the ATT and the ATC. Also, it implicitly equates social inequality with a situation in which those least likely to study abroad are most likely to benefit from it. At least from the perspective of social stratification theory, such a conclusion would (additionally) require an analysis of a manifest construct of social (dis)advantage, such as parents' education or professional status, so that the effects of ISM can actually be studied depending on graduates' adherence to different social strata.
} 
sampling, the DZHW Graduate Panel provides nationally representative data on graduates from universities and universities of applied sciences in Germany (for details, see Grotheer et al. 2012). To be able to study heterogeneous effects of ISM over a longer time of graduates' careers, we use data on the 2005 graduation cohort (https://doi.org/10.21249/DZHW:gra2005 :2.0.0). This cohort has so far been surveyed at one, five, and 10 years after graduation. The data are well-suited for our purposes because they provide precise measures of our dependent and independent variables of interest, and on various variables that may influence both participation in ISM and labour market success (for details, see the following section).

We apply a few sample restrictions to homogenise our sample: First, we focus on graduates from the traditional German degree programmes (mostly Diplom, Magister, and Staatsexamen), which are equivalent to the Master level. Graduates from Master degrees were not surveyed in the first wave of the 2005 DZHW Graduate Panel. Bachelor graduates were surveyed, but we exclude them because they are hard to compare with graduates of traditional German degrees due to their shorter time spent in higher education. In any case, both Bachelor and Master graduates still constituted very small shares of the population of all graduates in the 2005 cohort. Second, we exclude graduates who worked abroad at the time of the surveys, as differences in the stability of national economies and currencies make graduates' wages hard to compare across countries. Furthermore, we restrict our analysis to graduates from vocationally unspecific fields of study, that is, graduates from all fields but medicine and teacher training. We do this because previous research has suggested that studying abroad yields little or no returns in vocationally specific fields of study (Kratz and Netz 2018; Waibel et al. 2018). We have tested and verified that this pattern is visible in our data - among both graduates from high and low social origins. Finally, we exclude cases with extreme income values and graduates who stayed abroad for just one month (see the following section for details).

We use two analytical samples: For the PSM, we exclude cases with missing information using listwise deletion (1417 cases). For the growth curve analysis, we multiply impute data for cases with missing information (1739 cases).

\section{Variables}

Our dependent variable is graduates' gross annual labour income, which was measured at one, five, and 10 years after graduation. Labour income was captured in a rather detailed manner, so that we can use an income measure capturing both the base salary as well as additional fixed and variable salary components. To avoid that extreme outliers distort our results, we exclude the top and bottom 0.5 percent of the income distribution at 10 years after graduation ( 20 cases).

We capture ISM experience through a dummy variable indicating whether graduates have spent a consecutive time of at least two months outside Germany to complete a study period, an internship, a language course, or another study-related stay. We exclude graduates who indicated that they stayed abroad for just one month. We do this to be able to examine the effect of a somewhat more substantial treatment. As graduates were asked to round up the duration of their ISM experience to full months, excluding graduates who indicated one month of ISM experience makes sure that we do not consider graduates who stayed abroad for just a few days to be part of the treatment group.

We operationalise graduates' social origin based on their parents' educational attainment. We differentiate graduates from an academic background (at least one parent obtained a higher 
education degree) and graduates from a non-academic background (no parent obtained a higher education degree). With our data, we can best operationalise graduates' social origin based on parents' educational attainment, which previous research has shown to be highly influential in explaining educational decisions in Germany (Hillmert and Jacob 2010), including the decision to study abroad (Lörz et al. 2016). Clearly, we would also be interested in using alternative measures of graduates' social origin, such as parents' occupational status. However, our data contain only a crude measure of parents' occupational status, which is not compatible with established occupation-based classifications of the social origin.

Our data confirm the finding of previous research that ISM is a socially selective educational option: A first descriptive analysis shows that 42 percent of graduates from an academic background spent time abroad during their studies, as opposed to 27 percent of graduates from a non-academic background.

Besides the main variables of interest, our multivariate analyses include various variables that previous research has suggested to influence participation in ISM (Table 1). These variables may also influence labour market success, and are therefore possible selection variables to be considered when approximating the effect of ISM on labour income.

As key demographic variables influencing study abroad participation, we consider graduates' sex and their age at the time of the first survey. Previous research shows that being female tends to increase the likelihood of studying abroad (Böttcher et al. 2016; Salisbury et al. 2009), while greater age tends to decrease it (Messer and Wolter 2007; Netz 2015). Regarding effects on the labour market outcomes, being female tends to come along with disadvantages (Leuze and Strauß 2014), while greater age tends to come along with experience and seniority effects

Table 1 Distribution of selection variables, by social origin and ISM experience (shares in percent)

\begin{tabular}{|c|c|c|c|c|c|c|}
\hline & \multicolumn{3}{|c|}{ Academic background } & \multicolumn{3}{|c|}{ Non-academic background } \\
\hline & ISM & & No ISM & ISM & & No ISM \\
\hline Female (vs. male) & 54.9 & & 49.6 & 54.3 & + & 46.5 \\
\hline Age & & $* *$ & & & + & \\
\hline Younger than 27 & 29.5 & & 31.2 & 23.4 & & 24.1 \\
\hline $27-29$ & 59.7 & & 50.4 & 54.8 & & 46.5 \\
\hline 30 and older & 10.7 & & 18.5 & 21.8 & & 29.4 \\
\hline School type: Gymnasium (vs. other schools) & 90.9 & $* *$ & 82.7 & 78.7 & $* *$ & 68.0 \\
\hline Final school grade & & $* * *$ & & & $* *$ & \\
\hline Top $25 \%$ & 30.8 & & 21.1 & 21.3 & & 13.6 \\
\hline Middle group (50\%) & 52.9 & & 44.5 & 53.2 & & 47.5 \\
\hline Bottom $25 \%$ & 16.2 & & 34.4 & 25.5 & & 38.9 \\
\hline School location: East Germany (vs. West Germany) & 29.5 & & 34.9 & 17.0 & $*$ & 24.5 \\
\hline Born abroad & 3.2 & & 2.3 & 1.1 & & 3.0 \\
\hline Mobility in access to higher education & 42.9 & $* *$ & 33.3 & 35.1 & + & 27.6 \\
\hline Field of study & & $* * *$ & & & $* * *$ & \\
\hline Humanities & 19.2 & & 6.6 & 16.5 & & 7.9 \\
\hline Law, psychology, social sciences & 7.1 & & 15.9 & 6.9 & & 18.7 \\
\hline Economics & 13.3 & & 10.3 & 23.9 & & 12.6 \\
\hline STEM & 45.8 & & 53.2 & 41.0 & & 52.7 \\
\hline Other & 14.6 & & 14.1 & 11.7 & & 8.1 \\
\hline Graduation from excellence university & 36.7 & $* *$ & 25.1 & 34.6 & $* *$ & 22.1 \\
\hline
\end{tabular}

Data source: DZHW Graduate Panel $2005(N=1417)$

$* * * p<0.001, * * p<0.01, * p<0.05,{ }^{+} p<0.1$ ( $\chi^{2}$ test for differences between subsamples of graduates with ISM and without ISM) 
that can positively affect labour market outcomes (Dustmann and Meghir 2005). To ensure that our PSM is based on a sufficient region of common support, we consider three age groups instead of including age as a continuous variable.

Previous research has highlighted that experiences at school may influence the later likelihood of studying abroad: Academically oriented schools tend to offer better opportunity structures for learning foreign languages and for completing first stays abroad than vocationally oriented schools (Gerhards and Hans 2013). Attending academically oriented schools is therefore positively associated with studying abroad during higher education. Good grades are another factor positively influencing study abroad participation, as they can ease access to mobility programmes and scholarships (Lörz et al. 2016). In turn, a good academic performance tends to foster labour market success (Miller 1998). We therefore control for the type of school attended (academically oriented versus vocationally oriented school) and the final school grade (aggregated to three grade groups). To capture possible regional differences regarding the orientation towards international education, the preparation for studying abroad, and the sustained East-West pay gap (Brücker and Trübswetter 2007), we additionally take into account whether graduates have finished school in East Germany; the reference category comprises graduates who completed school in West Germany and a few graduates who completed school abroad.

Previous research has also shown that international mobility during childhood and youth is positively associated with international mobility during higher education (Brooks and Waters 2010; Lörz et al. 2016). In turn, spatial mobility during the educational career is associated with better labour market outcomes, as it can increase graduates' job search radius and job match, and lower their costs of becoming mobile (Kratz and Netz 2018). As measures of experience with mobility before entering higher education, we therefore consider whether graduates were born abroad and whether they were geographically mobile when accessing higher education. In detail, the latter variable indicates whether graduates have moved to Germany or to another federal state within Germany when entering higher education.

Various studies have documented notable differences in study abroad participation across fields of study (Böttcher et al. 2016; Hauschildt et al. 2018). These are arguably related to different traditions and necessities of studying abroad, as well as field-specific opportunity structures for staying abroad. Moreover, the field of study also influences labour market outcomes (Kirkeboen et al. 2016). We intend to capture these differences using five dummies for graduates' main field of study in our analyses.

Finally, we wish to capture institutional differences in the opportunity structures for going abroad. We do so using an indicator that identifies whether respondents graduated from a university that took part in the German excellence initiative (for detail, see Kehm and Pasternack 2009). This could be relevant for selection into ISM because universities with an excellence status are likely to be well-connected globally. Moreover, host universities should be more likely to accept students from elite institutions than from less renowned institutions. ${ }^{5}$ Graduating from universities with good research performance may also lead to better labour market outcomes (Ciriaci and Muscio 2014).

Regarding selection into ISM, we observe patterns for both social groups that are in line with the expectations that we have formulated based on previous research. Although the

\footnotetext{
5 The excellence initiative was announced in 2004 and initiated in 2007. However, universities which eventually succeeded in the competition must have had prestige and excellence in research already beforehand. We employ a dummy variable indicating whether a university was granted excellence status. As universities of applied sciences were not eligible to apply, we assigned all of them a value of 0 .
} 
observed differences are not always statistically significant, we find that being female, younger, graduating from the Gymnasium in West Germany with good grades, being mobile in access to higher education, graduating in the humanities or in economics and from an excellence university is associated with a higher likelihood of studying abroad (Table 1). The descriptive picture is contrary to our expectation only for (the very small group of) graduates from a low social origin who were born abroad.

In addition to the variables shown in Table 1, we also consider graduates' weekly working hours and months of work experience since graduation in the growth curve analysis. The reasons are explained in the next section.

\section{Methods}

In a first step, we describe the development of graduates' gross annual labour income at one, five, and 10 years after graduation. For both graduates from a high and from a low social origin, we analyse whether ISM experience is associated with a higher labour income and whether this association changes over the first 10 years of graduates' careers. We analyse the effects of ISM over this longer time frame because previous research has shown that monetary returns to ISM tend to be detectable only a few years after graduates' labour market entry (Iriondo 2020; Kratz and Netz 2018). Possibly, ISM leads to the acquisition of signals or human capital that become effective, observable, and thus remunerated only after a few years in labour market. By looking only at early career wages, scholars may miss out on the related income growth effect conditional on ISM.

In a second step, we estimate the effect of studying abroad on graduates' gross annual labour income using a PSM. PSM allows us to substantially reduce treatment selection bias (Rosenbaum and Rubin 1983), that is, the bias arising from the fact that individuals who study abroad have characteristics that influence both their likelihood of going abroad and their later labour market performance (for a more detailed discussion of this phenomenon, see, e.g., Kratz and Netz 2018; Messer and Wolter 2007).

In the literature examining labour market effects of ISM, PSM has recently become very popular. The reasons for this popularity include that - unlike many regression techniquesPSM forces researchers to critically reflect upon the process of individuals selecting into ISM. Also, it only compares very similar individuals who received and who did not receive the treatment (region of common support). Moreover, it presents a non-parametric method of causal inference, which makes no demanding assumptions about the distributions of variables and the functional form of their relationships (for details on the method and its potential for analysing effects of ISM, see Iriondo 2020; Waibel et al. 2018). A further and often unnoticed advantage of PSM is that it allows researchers to causally infer the effect of a treatment (in our case ISM) that tends to take place before the first measurement of the dependent variable of interest (in our case labour income). Importantly, however, PSM can only tackle observed selection into ISM. It cannot deal with further selection bias arising from unobserved heterogeneity between individuals going abroad and staying at home.

In our main analysis, we use an Epanechnikov kernel matching (for details on the employed Stata command, see Jann 2020). Compared with other matching algorithms, which yield similar results in our case (Table 2 in Appendix), the kernel matching makes a more comprehensive use of the available sample data and thus achieves a lower variance of the estimators (Gangl 2015). The balancing properties of the kernel matching were satisfied. As Fig. 5 and Table 3 in Appendix illustrate, it substantially reduces covariate bias. The mean bias 
after the matching lies below four for both social groups and can thus be considered appropriate (Gangl 2015).

As stated initially, we would also like to bring together the literatures studying heterogeneous effects (of ISM in particular and of educational options more generally) using either latent or manifest constructs to operationalise social (dis)advantage. Therefore, we examine the effect of studying abroad on gross annual labour income conditional on both graduates' social origin and their propensity to study abroad. This allows us to test the hypothesis that those least likely to study abroad benefit most from it (Di Pietro 2015; Waibel et al. 2018). More precisely, we can test whether or not this pattern is uniformly visible among graduates from a high and from a low social origin. To be able to study effects of ISM depending on the ISM propensity, we use the smoothing-differencing method developed by Xie et al. (2012).

In a final step, we ensure the robustness of our results through random effects (RE) growth curve models (for details, see Snijders and Bosker 2012). The adoption of a longitudinal perspective allows us to not only study wage level effects of ISM at one, five, and 10 years after graduation; it also allows us to study wage growth patterns contingent on ISM experience and the social origin. As we can combine the growth curve analysis with a multiple imputation by chained equations (MICE; for details, see White et al. 2011), this step also minimises possible bias resulting from the exclusion of cases with missing information. The variable with most missing values is working hours at wave one. The weekly working hours were not captured for graduates working full-time during the first survey wave. Together with all other variables included in the RE models, we therefore imputed the concerned values using information from all three survey waves. ${ }^{6}$

By controlling for graduates' working time in the RE models, we ensure that our results are not biased simply because graduates who studied abroad work more hours than those who did not study abroad. By additionally controlling for graduates' months of work experience since graduation, we rule out that one of these groups benefits from seniority effects more strongly than the other group.

\section{Results}

\section{Descriptive results}

Our descriptive analysis shows that graduates who temporarily studied abroad tend to receive a higher gross annual labour income than those who did not (Fig. 1). While the absolute ISM income gap is small at labour market entry, it increases over the first 10 years of graduates' careers.

Importantly, the observed ISM income gaps and the ISM income growth pattern are more expressed among graduates from an academic background than among graduates from a nonacademic background. In fact, we observe substantial and statistically significant ISM income differences only among graduates from an academic background, and only at five and 10 years after graduation.

\footnotetext{
${ }^{6}$ The imputation models we present in this article are based on 25 iterations and include all variables used for the PSM as well as information on working hours, work experience in months, family status, and possible parenthood. Following Young and Johnson (2010), we also imputed the dependent variable. If we do not impute the dependent variable, our estimates change only very marginally.
} 

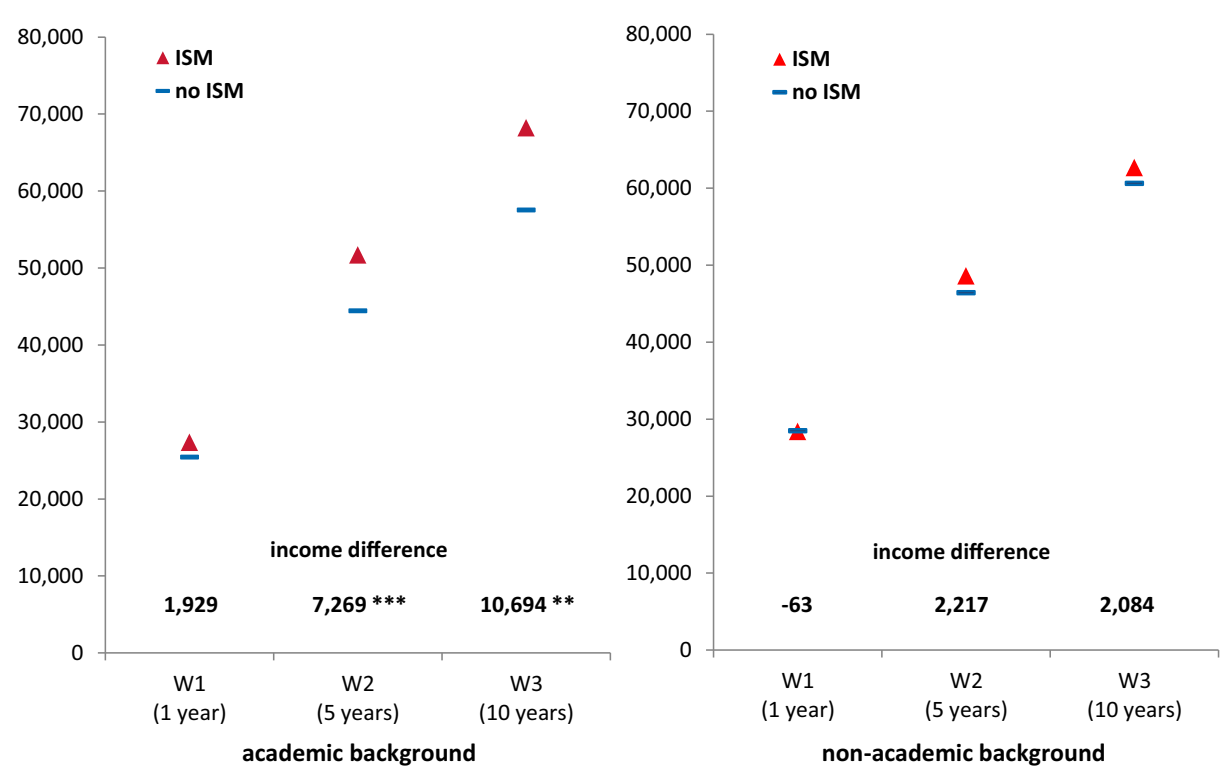

Fig. 1 Development of gross annual labour income, by social origin and ISM experience (in Euro). Data source: DZHW Graduate Panel $2005(N=1417)$. $* * * p<0.001, * * p<0.01, * p<0.05$. In our descriptive analyses, we employed the weights provided by the DZHW to correct for unit non-response and selective panel attrition

\section{Results of propensity score matching}

To deal with observed selection into ISM, we implemented an Epanechnikov kernel matching. We report the average treatment effect on the treated (ATT) for graduates from both social groups. The PSM broadly confirms the results of the descriptive analysis (Fig. 2).

After the PSM, we observe statistically significant effects of studying abroad on the annual labour income among graduates from an academic background for all three survey waves (3751 Euro at one year after graduation, 6544 Euro at five years after graduation, and 10,636 Euro at 10 years after graduation). These ISM income gaps increase in magnitude throughout the early career. Among graduates from a non-academic background, in contrast, we observe substantially smaller and insignificant effects, which do not drastically change throughout the early career (883 Euro at one year after graduation, 2191 Euro at five years after graduation, and 1509 Euro at 10 years after graduation).

As a robustness check, we also use alternative matching algorithms for the PSM (nearest neighbour matching with five neighbours and caliper matching). Moreover, we reran the kernel matching, thereby additionally including the weights provided by the DZHW to correct for unit non-response and selective panel attrition as a further covariate. These analyses confirm the pattern of results we obtained through the kernel matching (Table 2).

In the next step, we estimate the effect of studying abroad on labour income conditional on the propensity to study abroad. We focus on the annual labour income at 10 years after graduation. This analysis confirms the finding of Waibel et al. (2018) that the estimated returns to studying abroad are highest among those least likely to study abroad (Fig. 6 in Appendix).

However, we can additionally show that this pattern is driven by the results for graduates from an academic background (Fig. 3): Within this social group, the effect of studying abroad on labour income tends to decrease with the propensity to study abroad. Among graduates 


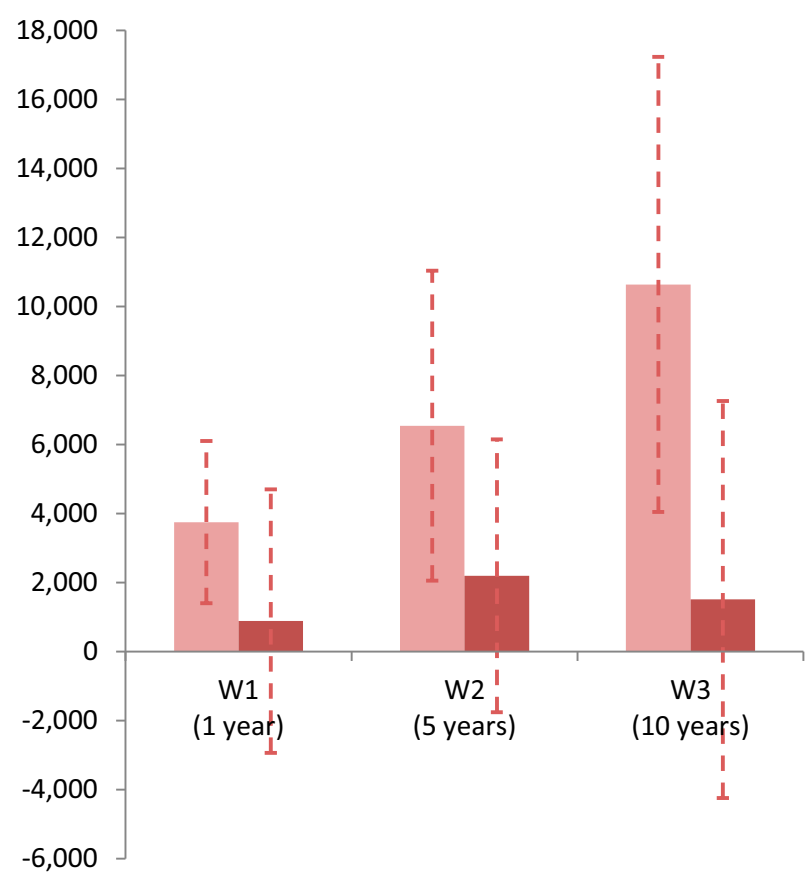

\section{academic background \\ non-academic background}

Fig. 2 Effect of ISM on graduates' gross annual labour income after kernel matching, by social origin (in Euro). Data source: DZHW Graduate Panel $2005(N=1417)$. The bars show estimated average treatment effects on the treated (ATT). The vertical dashed lines indicate $95 \%$ confidence intervals, which were calculated based on bootstrapped standard errors (Jann 2020)

from a non-academic background, in contrast, graduates with a higher propensity to study abroad seem to experience the largest monetary returns to studying abroad (in addition to graduates with an extremely low propensity to study abroad).
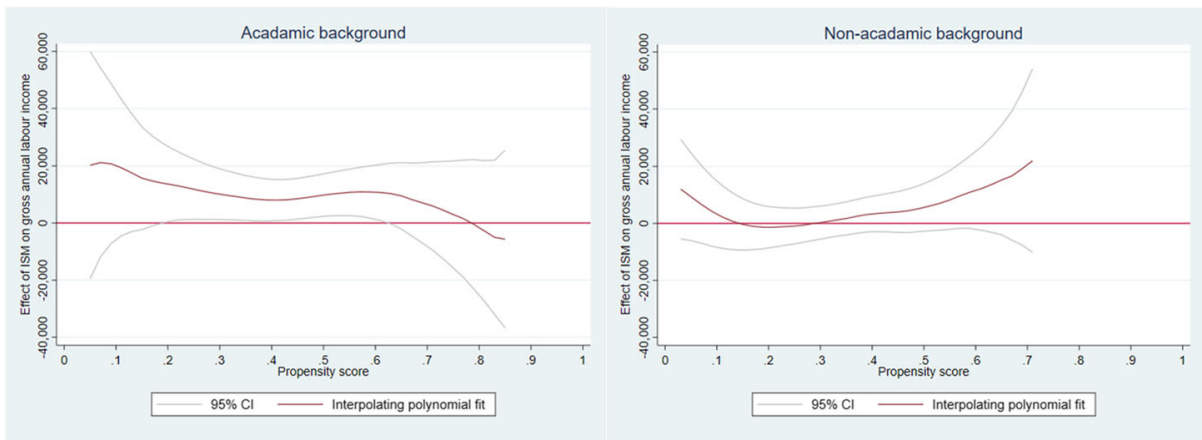

Fig. 3 Effect of ISM on gross annual labour income at 10 years after graduation, conditional on propensity score, by social origin (in Euro). Data source: DZHW Graduate Panel 2005 ( $N=1417)$. Results were estimated using the smoothing-differencing method developed by Xie et al. (2012). The grey lines indicate $95 \%$ confidence intervals (CI). The lines and corresponding CIs do not range across the entire $x$-axis because the empirically observed propensity scores do not range from 0 to 100 
Due to low case numbers of individuals with specific propensity scores, the estimated treatment effects are insignificant for parts of the propensity score distribution. The results thus need to be read with caution. Still, we think that they illustrate the utility of analysing heterogeneous effects of ISM conditional on both graduates' social origin and their propensity to study abroad.

\section{Results of RE growth curve analysis}

To further ensure the robustness of our results, we estimated RE growth curve models that additionally include graduates' weekly working hours as well as months of work experience since graduation and use multiply imputed data (Fig. 4). Again, these models suggest that graduates from an academic background benefit slightly more from studying abroad than graduates from a non-academic background. Thus, the results of the PSM do not seem to be substantially biased by missing data or by the working time and experience differing across social groups.

The RE models confirm that the effect of studying abroad on labour income is larger among graduates from an academic background (3151 Euro at one year after graduation, 5459 Euro at five years after graduation, and 7767 Euro at 10 years after graduation) than among graduates from a non-academic background (1443 Euro at one year after graduation, 2902 Euro at five years after graduation, and 4360 Euro at 10 years after graduation).

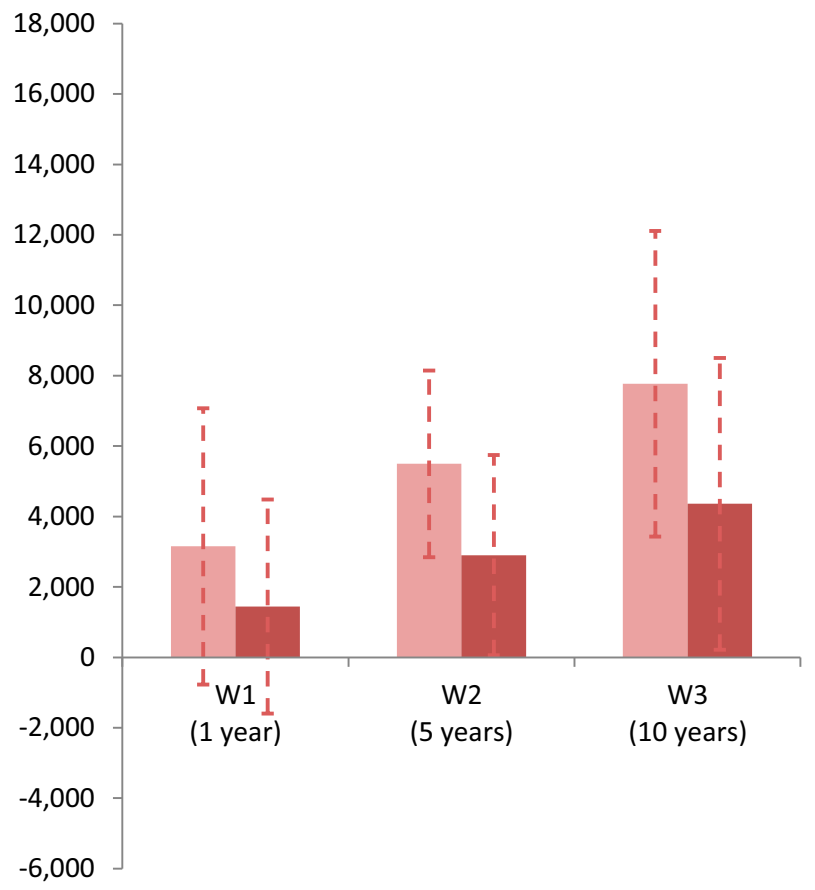

\footnotetext{
academic background

non-academic background
}

Fig. 4 RE growth curve model of gross annual labour income during the first 10 years after graduation, by social origin (in Euro). Data source: DZHW Graduate Panel 2005 ( $N=1739)$. The vertical dashed lines indicate 95\% confidence intervals 
As opposed to the results of the PSM, the estimated effects are now insignificant for both social groups at one year after graduation, and significant for both social groups at five and 10 years after graduation. Moreover, the RE models indicate smaller income effects of ISM for graduates from an academic background, and slightly larger effects for graduates from a nonacademic background. Still, we find the main result of the PSM to be confirmed by the RE models: Regarding the labour income in the early career, graduates from an academic background seem to benefit slightly more from studying than graduates from a non-academic background.

To better understand the differences between the results of the PSM and the RE models, we additionally estimated an RE model using the same variables as in the PSM. This RE model shows very similar results as the PSM does. However, it predicts a slightly higher (yet not significant) return to studying abroad among graduates from a non-academic background in the third wave. This can be explained by the parametric approach and (linear) functional form of the RE model. Largely, the differences between the PSM and the fully specified RE model are attributable to the additional information on working hours and work experience as well as the use of multiply imputed data.

\section{Discussion and conclusion}

\section{Main results}

Drawing on social stratification theory, we have tested whether the effect of studying abroad on graduates' labour income varies across social groups in the German labour market. Using data from the 2005 DZHW Graduate Panel, we have performed a PSM and calculated RE growth curve models to examine the role of ISM for the development of social inequality during the first 10 years of graduates' careers.

In line with the scenario of cumulative advantage, our results suggest that graduates from a high social origin benefit slightly more from ISM than graduates from a low social origin. After the PSM, we have observed significantly positive effects of ISM on labour income among graduates from a high social origin, but no significant effect among graduates from a low social origin. The RE growth curve models - which were meant to ensure the robustness of our results by using multiply imputed data and by including additional information on graduates' working regimes - have confirmed this result and shown that graduates from a high social origin experience a slightly more pronounced income growth in relation to their ISM experience.

As mentioned initially, various studies have shown that individuals from a high social origin are more likely to study abroad than those from a low social origin (Di Pietro 2019; Hauschildt et al. 2018; Lingo 2019; Netz and Finger 2016; Salisbury et al. 2009; Wiers-Jenssen 2011). Adding to this state of research, our study has shown that graduates from a high social origin are not only more likely to study abroad in the first place, but that they also benefit slightly more from studying abroad. ${ }^{7}$ Against this background, we conclude that ISM tends to foster the reproduction of social inequality in the German labour market.

On a broader methodological note, we wanted to show that for studying effect heterogeneity depending on social (dis)advantage, it matters whether scholars use manifest or latent constructs. More precisely, we reckon that the combination of both approaches can be particularly fruitful. In

\footnotetext{
${ }^{7}$ This conclusion applies to graduates from vocationally unspecific fields of study, that is, graduates from all fields but medicine and teacher training. We restricted our analyses to these graduates because we did not find monetary returns to studying abroad among graduates from medicine and teacher training for neither social group.
} 
line with Waibel et al. (2018), who have examined the effect of studying abroad on graduates' occupational status in the German labour market, we found that the estimated returns to ISM are highest among those exhibiting the lowest propensity of studying abroad.

Regarding the possible reproduction of social inequality, however, we draw a slightly different conclusion than Waibel et al. (2018). By studying the effect of ISM on labour income conditional on both the educational attainment of graduates' parents and on the propensity of studying abroad, we have shown that the pattern of those least likely to study abroad benefiting most is driven by the results for graduates from a high social origin. Among graduates from a low social origin, those with a higher ISM propensity are most likely to benefit from studying abroad in terms of labour income. In the subsection on further research, we propose several hypotheses why this might be the case.

\section{Limitations}

Our study has several limitations, which highlight ways forward for research in the field. First, our data captured only the first 10 years of graduates' employment history. While this is a longer time frame than most existing studies could examine, we cannot test whether graduates from a low social origin benefit from study abroad experience relatively more strongly than graduates from a high social origin during their long-term career. If this was the case, we might have to reconsider our conclusion that ISM increases social inequality in the German labour market.

Further unobserved heterogeneity between graduates from different social origins and with or without ISM experience constitutes a second possible limitation of our study. We have tried to minimise selection bias by thoroughly considering self-selection into ISM. However, our PSM and RE growth curve models can only capture selection bias based on graduates' observed characteristics (for an elaborate discussion of the role of unobserved heterogeneity for the analysis of labour market effects of spatial mobility, see Di Cintio and Grassi 2017). Thus, research in the field would benefit from studies using methods that can better deal with unobserved heterogeneity, and from studies using panel data that include additional plausible selection variables, such as students' personality traits, motivation for studying abroad, and their expectations on returns to studying abroad.

A third limitation of our study is its inability to precisely determine which of the theoretically plausible mechanisms explain(s) the outcome we observed. As we elaborate in the following subsection, addressing this issue constitutes a very promising avenue for further research in the field.

\section{Further research}

Our knowledge on heterogeneous labour market effects of studying abroad could not only be advanced by using more comprehensive data and more advanced longitudinal methods but also by addressing further substantive research questions arising from the results of our study. Most notably, we think that our study, which asked whether ISM increases social inequality in the German labour market, could be followed by studies looking more closely at mechanisms explaining why this is the case.

In this respect, it matters whether the process of selecting into ISM based on the personality, motivation, and return expectations differs between individuals from high and low social origins. As hypothesised in the theory section, individuals from a low social origin could decide to study abroad only if they are particularly skilled, motivated, and strongly convinced of the benefits of doing so. At first glance, our results do not seem to align with the hypothesis that individuals from a low social origin going abroad are more strongly positively self-selected than those from a high social origin, as we observe that the former benefit relatively less regarding their labour income. 
Moreover, it could be further examined whether the marginal utility of studying abroad differs for individuals from high and low origins in terms of their skill acquisition (for an example, see Sorrenti 2017): Do individuals from different social groups acquire different types and amounts of skills while abroad?

Further possible explanations for the observed patterns relate to differences in the extent to which individuals from different social groups can valorise their ISM experience on the labour market (Waters 2009). On the one hand, it could be tested whether graduates from a high social origin benefit more from ISM experience because they enter labour market segments and employers that (can) reward ISM experience particularly well (for a discussion of how the employment context may moderate the effects of ISM, see Kratz and Netz 2018; Waibel et al. 2018; WiersJenssen and Try 2005). On the other hand, further research could assess whether graduates from a high social origin can better sell their ISM experience in application procedures, job interviews, and on-the-job negotiations than graduates from a low social origin, possibly in relation to habitual advantages and skills that they have acquired during earlier socialisation processes. ${ }^{8}$

Importantly, it is well possible that the mechanisms of compensatory levelling and of cumulative advantage are at play simultaneously. It is theoretically plausible that individuals from a low social origin benefit more from ISM in terms of their skills acquisition, but thateventually - individuals from a high social origin are better able to valorise an ISM signal in their specific labour market segment and position.

Both the hypothesis on differential skill acquisition and the hypothesis on differential valorisation of the acquired skills in the labour market could be drawn upon to better explain our finding that returns to ISM tend to decrease with a rising propensity to study abroad among graduates from a high social origin, while they tend to increase among graduates from a low social origin. Possibly, it is particularly graduates from a low social origin with a rather low propensity to study abroad who lack the linguistic and cultural preparation to avail themselves of the benefits of ISM, as suggested by Di Pietro (2015).

Finally, the relationship between the expansion of ISM programmes and the development of social inequality deserves more attention in further research. Evidence from Germany (Netz and Finger 2016) and the USA (Kramer and Wu 2019) suggests that the introduction of major student aid schemes has particularly boosted study abroad participation among students from a high social origin. Yet, it remains to be examined in detail whether existing policies have increased or decreased inequality in access to ISM, and which policies enable a particularly fruitful personality, skill, and eventually also professional development. Such analyses will provide further theoretically and politically valuable knowledge on the types of policies that increase and decrease social inequality in the education system and the labour market.

\section{Research ethics}

The results presented in this article do not allow for deductive disclosure of the survey participants' identities. Participation in the survey was voluntary and participants' confidentiality was protected.

\footnotetext{
${ }^{8}$ As mentioned in the theory section, further research would also benefit from a stricter methodological separation of treatment heterogeneity and moderated treatment effects. Applied to our research question, this would call for a better examination of whether graduates from a high social origin complete different and potentially more rewarding types of stays abroad, whether they simply manage to benefit more from the same types of stays abroad, or both.
} 
Acknowledgements We are grateful for open access funding provided by the DEAL project. We thank Thorsten Euler and Marten Wallis for their valuable support during the data processing.

\section{Compliance with ethical standards}

Conflict of interest The authors declare that they have no conflicts of interest.

\section{Appendix}
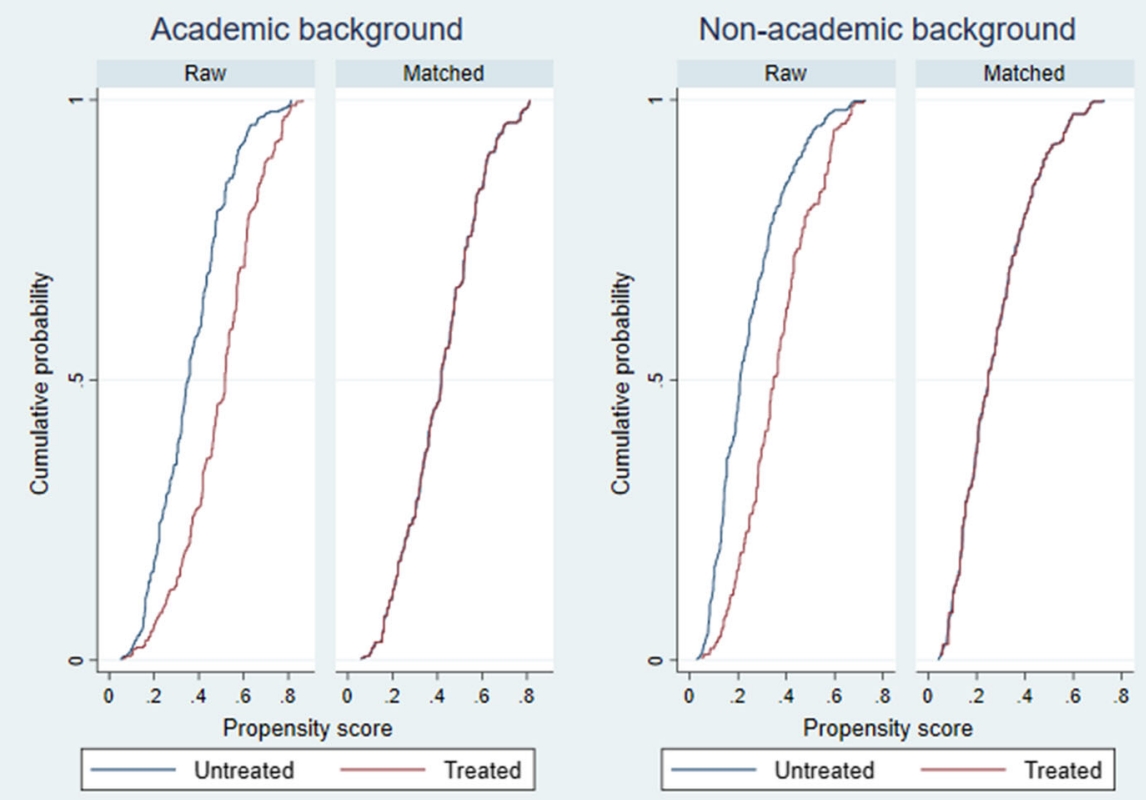

Fig. 5 Quality of the kernel matching: Cumulative distribution functions of propensity scores before and after the PSM, by social origin. Data source: DZHW Graduate Panel $2005(N=1417)$ 


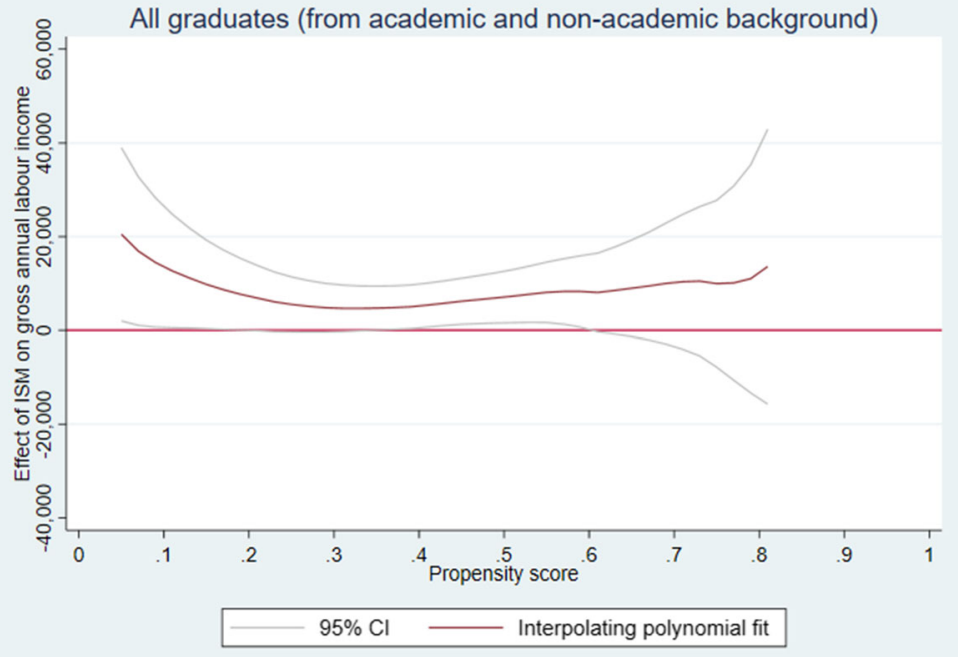

Fig. 6 Effect of ISM on gross annual labour income at 10 years after graduation, conditional on propensity score (in Euro). Data source: DZHW Graduate Panel $2005(N=1417)$

Table 2 Effect of ISM on gross annual labour income estimated by alternative matching algorithms (in Euro)

\begin{tabular}{|c|c|c|c|c|c|c|c|}
\hline \multirow{2}{*}{$\begin{array}{l}\text { Matching } \\
\text { algorithm }\end{array}$} & \multirow{2}{*}{$\begin{array}{l}\text { Cases } \\
\text { out of } \\
\text { common } \\
\text { support }\end{array}$} & \multicolumn{2}{|l|}{ W1 (1 year) } & \multicolumn{2}{|l|}{ W2 (5 years) } & \multicolumn{2}{|c|}{ W3 (10 years) } \\
\hline & & $\begin{array}{l}\text { Academic } \\
\text { background }\end{array}$ & $\begin{array}{l}\text { Non- } \\
\text { academic } \\
\text { background }\end{array}$ & $\begin{array}{l}\text { Academic } \\
\text { background }\end{array}$ & $\begin{array}{l}\text { Non- } \\
\text { academic } \\
\text { background }\end{array}$ & $\begin{array}{l}\text { Academic } \\
\text { background }\end{array}$ & $\begin{array}{l}\text { Non- } \\
\text { academic } \\
\text { background }\end{array}$ \\
\hline Kernel & 66 & 3751 & 883 & 6544 & 2192 & 10,636 & 1509 \\
\hline $\begin{array}{l}\text { Nearest } \\
\text { neighbour (5) }\end{array}$ & 218 & 3294 & 273 & 6367 & 1680 & 9278 & 786 \\
\hline Caliper $(0.001)$ & 107 & 4006 & 1065 & 4524 & 1575 & 9828 & -517 \\
\hline $\begin{array}{l}\text { Kernel (including } \\
\text { weights) }\end{array}$ & 169 & 4696 & 962 & 8012 & 1537 & 11,070 & 2420 \\
\hline
\end{tabular}

Data source: DZHW Graduate Panel $2005(N=1417)$. The table shows average treatment effects on the treated (ATT). 
Table 3 Quality of the PSM: Distribution of selection variables after kernel matching, by social origin and ISM experience (shares in percent)

\begin{tabular}{|c|c|c|c|c|c|c|c|c|}
\hline & \multicolumn{4}{|c|}{ Academic background } & \multicolumn{4}{|c|}{ Non-academic background } \\
\hline & $\begin{array}{l}\text { Treated } \\
\text { (ISM) }\end{array}$ & $\begin{array}{l}\text { Controls } \\
\text { (no ISM) }\end{array}$ & $\begin{array}{l}\% \text { Bias } \\
\text { before } \\
\text { matching }\end{array}$ & $\begin{array}{l}\% \text { Bias } \\
\text { after } \\
\text { matching }\end{array}$ & $\begin{array}{l}\text { Treated } \\
\text { (ISM) }\end{array}$ & $\begin{array}{l}\text { Controls } \\
\text { (no ISM) }\end{array}$ & $\begin{array}{l}\% \text { Bias } \\
\text { before } \\
\text { matching }\end{array}$ & $\begin{array}{l}\% \text { Bias } \\
\text { after } \\
\text { matching }\end{array}$ \\
\hline Female (vs. male) & 49.1 & 51.0 & 10.5 & -3.8 & 46.9 & 48.0 & 15.8 & -2.2 \\
\hline \multicolumn{9}{|c|}{ Age (reference category: Younger than 27) } \\
\hline $27-29$ & 30.0 & 30.5 & -3.5 & -1.0 & 23.3 & 24.1 & -1.6 & -2.0 \\
\hline 30 and older & 52.9 & 55.0 & 18.9 & -4.2 & 47.8 & 49.0 & 16.9 & -2.5 \\
\hline $\begin{array}{l}\text { School type: } \\
\text { Gymnasium (vs. } \\
\text { other schools) }\end{array}$ & 88.8 & 87.2 & -24.5 & -4.8 & 72.3 & 70.6 & -24.8 & -3.8 \\
\hline \multicolumn{9}{|c|}{ Final school grade (reference category: top $25 \%$ ) } \\
\hline Middle group (50\%) & 49.1 & 47.6 & 16.9 & 2.8 & 45.9 & 49.9 & 11.6 & -8.1 \\
\hline Bottom $25 \%$ & 28.0 & 27.0 & -42.7 & 2.3 & 38.0 & 35.3 & -29.2 & 5.7 \\
\hline $\begin{array}{l}\text { School location: East } \\
\text { Germany (vs. West } \\
\text { Germany) }\end{array}$ & 32.6 & 32.7 & -11.4 & -3.0 & 22.2 & 23.6 & -18.9 & -3.4 \\
\hline Born abroad & 3.3 & 2.7 & 5.5 & 3.4 & 2.1 & 2.3 & -13.9 & -1.9 \\
\hline $\begin{array}{l}\text { Mobility in access to } \\
\text { higher education }\end{array}$ & 38.5 & 36.2 & 19.8 & 4.7 & 26.4 & 30.3 & 16.4 & -8.5 \\
\hline \multicolumn{9}{|c|}{ Field of study (reference category: humanities) } \\
\hline $\begin{array}{l}\text { Law, psychology, } \\
\text { social sciences }\end{array}$ & 10.1 & 12.5 & -27.7 & -7.6 & 14.6 & 15.0 & -35.6 & -1.0 \\
\hline Economics & 11.2 & 11.8 & 9.3 & -1.8 & 17.0 & 16.3 & 30.0 & 1.7 \\
\hline STEM & 52.1 & 52.0 & -14.8 & 1.4 & 48.6 & 50.6 & -23.9 & -3.9 \\
\hline Other & 16.6 & 13.2 & 1.6 & 9.7 & 9.1 & 8.6 & 12.1 & 2.0 \\
\hline $\begin{array}{l}\text { Graduation from } \\
\text { excellence university }\end{array}$ & 29.8 & 31.5 & 25.3 & -3.6 & 26.6 & 25.8 & 28.0 & 1.8 \\
\hline Mean standardised bias & & & 16.6 & 3.9 & & & 19.9 & 3.5 \\
\hline
\end{tabular}

Data source: DZHW Graduate Panel $2005(N=1417)$

Open Access This article is licensed under a Creative Commons Attribution 4.0 International License, which permits use, sharing, adaptation, distribution and reproduction in any medium or format, as long as you give appropriate credit to the original author(s) and the source, provide a link to the Creative Commons licence, and indicate if changes were made. The images or other third party material in this article are included in the article's Creative Commons licence, unless indicated otherwise in a credit line to the material. If material is not included in the article's Creative Commons licence and your intended use is not permitted by statutory regulation or exceeds the permitted use, you will need to obtain permission directly from the copyright holder. To view a copy of this licence, visit http://creativecommons.org/licenses/by/4.0/.

\section{References}

Böttcher, L., Araújo, N., Nagler, J., Mendes, J., Helbing, D., \& Herrmann, H. (2016). Gender gap in the ERASMUS mobility program. PLoS One, 11(2), e0149514. https://doi.org/10.1371/journal.pone.0149514.

Bourdieu, P. (1984). Distinction: a social critique of the judgement of taste. Cambridge, MA: Harvard University Press.

Brand, J., \& Xie, Y. (2010). Who benefits most from college? Evidence for negative selection in heterogeneous economic returns to higher education. American Sociological Review, 75(2), 273-302. https://doi. org/10.1177/0003122410363567. 
Brooks, R., \& Waters, J. (2010). Social networks and educational mobility: the experiences of UK students. Globalisation, Societies and Education, 8(1), 143-157. https://doi.org/10.1080/14767720903574132.

Brücker, H., \& Trübswetter, P. (2007). Do the best go west? An analysis of the self-selection of employed EastWest migrants in Germany. Empirica, 34(4), 371-395. https://doi.org/10.1007/s10663-006-9031-y.

Ciriaci, D., \& Muscio, A. (2014). University choice, research quality and graduates' employability: evidence from Italian national survey data. European Educational Research Journal, 13(2), 199-219. https://oi. org/10.2304/eerj.2014.13.2.199.

Di Cintio, M., \& Grassi, E. (2017). International mobility and wages: an analysis of Italian Ph.D. graduates. The Annals of Regional Science, 59(3), 759-791. https://doi.org/10.1007/s00168-016-0749-6.

Di Pietro, G. (2015). Do study abroad programs enhance the employability of graduates? Education Finance and Policy, 10(2), 223-243. https://doi.org/10.1162/EDFP_a_00159.

Di Pietro, G. (2019). Changes in socioeconomic inequality in access to study abroad programs: a cross-country analysis. Research in Social Stratification and Mobility. https://doi.org/10.1016/j.rssm.2019.100465.

DiPrete, T., \& Eirich, G. (2006). Cumulative advantage as a mechanism for inequality: a review of theoretical and empirical developments. Annual Review of Sociology, 32, 271-297. https://doi.org/10.1146/annurev. soc.32.061604.123127.

Dustmann, C., \& Meghir, C. (2005). Wages, experience and seniority. The Review of Economic Studies, 72(1), 77-108. https://doi.org/10.1111/0034-6527.00325.

Gangl, M. (2015). Matching estimators for treatment effects. In H. Best \& C. Wolf (Eds.), The SAGE handbook of regression analysis and causal inference (pp. 251-276). Los Angeles: SAGE. https://doi.org/10.4135 /9781446288146.n12

Gerhards, J., \& Hans, S. (2013). Transnational human capital, education, and social inequality. Analyses of international student exchange. Zeitschrift für Soziologie, 42(2), 99-117. https://doi.org/10.1515/zfsoz-2013-0203.

Grotheer, M., Isleib, S., Netz, N., \& Briedis, K. (Eds.). (2012). Hochqualifiziert und gefragt. Ergebnisse der zweiten HIS-HF Absolventenbefragung des Jahrgangs 2005. Hannover: HIS GmbH.

Hauschildt, K., Vögtle, E., \& Gwosć, C. (2018). Social and economic conditions of student life in Europe. EUROSTUDENT VI 2016-2018. Bielefeld: W. Bertelsmann Verlag.

Hillmert, S., \& Jacob, M. (2010). Selections and social selectivity on the academic track: a life-course analysis of educational attainment in Germany. Research in Social Stratification and Mobility, 28(1), 59-76. https://oi. org/10.1016/j.rssm.2009.12.006.

Iriondo, I. (2020). Evaluation of the impact of Erasmus study mobility on salaries and employment of recent graduates in Spain. Studies in Higher Education, 45(4), 925-943. https://doi.org/10.1080 /03075079.2019.1582011.

Jacob, M., Kühhirt, M., \& Rodrigues, M. (2019). Labour market returns to graduates' international experience: exploring cross-country variation in Europe. European Sociological Review, 35(4), 491-505. https://doi. org/10.1093/esr/jcz022.

Jann, B. (2020). KMATCH: Stata module module for multivariate-distance and propensity-score matching, including entropy balancing, inverse probability weighting, (coarsened) exact matching, and regression adjustment. https://econpapers.repec.org/software/bocbocode/s458346.htm. Accessed 01/03/2020.

Kehm, B., \& Pasternack, P. (2009). The German 'Excellence Initiative' and its role in restructuring the national higher education landscape. In D. Palfreyman \& T. Tapper (Eds.), Structuring mass higher education: the role of elite institutions (pp. 113-127). London: Routledge.

Kirkeboen, L., Leuven, E., \& Mogstad, M. (2016). Field of study, earnings, and self-selection. The Quarterly Journal of Economics, 131(3), 1057-1111. https://doi.org/10.1093/qje/qjw019.

Kramer, D., \& Wu, J. (2019). A HOPE for study abroad: evidence from Tennessee on the impact of merit-aid policy adoption on study abroad participation. Educational Policy. https://doi.org/10.1177 /0895904818823752.

Kratz, F., \& Netz, N. (2018). Which mechanisms explain monetary returns to international student mobility? Studies in Higher Education, 43(2), 375-400. https://doi.org/10.1080/03075079.2016.1172307.

Kuhn, T. (2016). The social stratification of European schoolchildren's transnational experiences: a cross-country analysis of the International Civics and Citizenship Study. European Sociological Review, 32(2), 266-279. https://doi.org/10.1093/esr/jcv097.

Laurison, D., \& Friedman, S. (2016). The class pay gap in higher professional and managerial occupations. American Sociological Review, 81(4), 668-695. https://doi.org/10.1177 $/ 0003122416653602$.

Leuze, K., \& Strauß, S. (2014). Female-typical subjects and their effect on wage inequalities among higher education graduates in Germany. European Societies, 16(2), 275-298. https://doi. org/10.1080/14616696.2012.748929.

Lingo, M. (2019). Stratification in study abroad participation after accounting for student intent. Research in Higher Education, 60(8), 1142-1170. https://doi.org/10.1007/s11162-019-09545-z. 
Liwiński, J. (2019a). Does it pay to study abroad? Evidence from Poland. International Journal of Manpower, 40(3), 525-555. https://doi.org/10.1108/IJM-11-2017-0305.

Liwiński, J. (2019b). Does studying abroad enhance employability? Economics of Transition and Institutional Change, 27(2), 409-423. https://doi.org/10.1111/ecot.12203.

Lörz, M., Netz, N., \& Quast, H. (2016). Why do students from underprivileged families less often intend to study abroad? Higher Education, 72(2), 153-174. https://doi.org/10.1007/s10734-015-9943-1.

Lucas, S. (2001). Effectively maintained inequality: education transitions, track mobility, and social background effects. American Journal of Sociology, 106(6), 1642-1690. https://doi.org/10.1086/321300.

Messer, D., \& Wolter, S. (2007). Are student exchange programs worth it? Higher Education, 54(5), 647-663. https://doi.org/10.1007/s10734-006-9016-6.

Miller, S. (1998). Shortcut: high school grades as a signal of human capital. Educational Evaluation and Policy Analysis, 20(4), 299-311. https://doi.org/10.3102/01623737020004299.

Morgan, S., \& Winship, C. (2014). Counterfactuals and causal inference: methods and principles for social research (2nd ed.). Cambridge, MA: Cambridge University Press.

Netz, N. (2015). What deters students from studying abroad? Evidence from four European countries and its implications for higher education policy. Higher Education Policy, 28(2), 151-174. https://doi.org/10.1057/hep.2013.37.

Netz, N., \& Finger, C. (2016). New horizontal inequalities in German higher education? Social selectivity of studying abroad between 1991 and 2012. Sociology of Education, 89(2), 79-98. https://doi.org/10.1177 $/ 0038040715627196$.

Netz, N., Klasik, D., Entrich, S., \& Barker, M. (2020). Socio-demographics: a global overview of inequalities in education abroad participation. In A. Ogden, B. Streitwieser, \& C. Van Mol (Eds.), Education abroad: bridging scholarship and practice (pp. 28-42). New York: Routledge.

Petzold, K. (2017). Studying abroad as a sorting criterion in the recruitment process: a field experiment among German employers. Journal of Studies in International Education, 21(5), 412-430. https://doi.org/10.1177 $/ 1028315317697543$.

Petzold, K. (2020). Heterogeneous effects of graduates' international mobility on employers' hiring intentionsexperimental evidence from Germany. Higher Education. https://doi.org/10.1007/s10734-020-00524-3.

Pinto, F. (2020). The effect of university graduates' international mobility on labour outcomes in Spain. Studies in Higher Education. https://doi.org/10.1080/03075079.2020.1725877.

Rosenbaum, P., \& Rubin, D. (1983). The central role of the propensity score in observational studies for causal effects. Biometrika, 70(1), 41-55. https://doi.org/10.1093/biomet/70.1.41.

Roy, A., Newman, A., Ellenberger, T., \& Pyman, A. (2019). Outcomes of international student mobility programs: a systematic review and agenda for future research. Studies in Higher Education, 44(9), 16301644. https://doi.org/10.1080/03075079.2018.1458222.

Salisbury, M., Umbach, P., Paulsen, M., \& Pascarella, E. (2009). Going global: understanding the choice process of the intent to study abroad. Research in Higher Education, 50(2), 119-143. https://doi.org/10.1007 /s11162-008-9111-x.

Schafer, M., Wilkinson, L., \& Ferraro, K. (2013). Childhood (mis)fortune, educational attainment, and adult health: contingent benefits of a college degree? Social Forces, 91(3), 1007-1034. https://doi.org/10.1093/sf/sos192.

Schindler, S., \& Reimer, D. (2011). Differentiation and social selectivity in German higher education. Higher Education, 61(3), 261-275. https://doi.org/10.1007/s10734-010-9376-9.

Schnepf, S., \& Colagrossi, M. (2020). Is unequal uptake of Erasmus mobility really only due to students' choices? The role of selection into universities and fields of study. Journal of European Social Policy. https://doi.org/10.1177/0958928719899339.

Schofer, E., \& Meyer, J. (2005). The worldwide expansion of higher education in the twentieth century. American Sociological Review, 70(6), 898-920. https://doi.org/10.1177/000312240507000602.

Snijders, T., \& Bosker, R. (2012). Multilevel analysis: an introduction to basic and advanced multilevel modeling (2nd ed.). London: Sage Publications.

Sorrenti, G. (2017). The Spanish or the German apartment? Study abroad and the acquisition of permanent skills. Economics of Education Review, 60, 142-158. https://doi.org/10.1016/j.econedurev.2017.07.001.

Triventi, M. (2013). Stratification in higher education and its relationship with social inequality: a comparative study of 11 European countries. European Sociological Review, 29(3), 489-502. https://doi.org/10.1093/esr/jcr092.

Triventi, M., Vergolini, L., \& Zanini, N. (2017). Do individuals with high social background graduate from more rewarding fields of study? Changing patterns before and after the 'Bologna process'. Research in Social Stratification and Mobility, 51(Supplement C), 28-40. https://doi.org/10.1016/j.rssm.2017.07.001.

Van De Werfhorst, H., Sullivan, A., \& Cheung, S. (2003). Social class, ability and choice of subject in secondary and tertiary education in Britain. British Educational Research Journal, 29(1), 41-62. https://doi. org/10.1080/0141192032000057366.

Van Mol, C. (2017). Do employers value international study and internships? A comparative analysis of 31 countries. Geoforum, 78, 52-60. https://doi.org/10.1016/j.geoforum.2016.11.014. 
Waibel, S., Rüger, H., Ette, A., \& Sauer, L. (2017). Career consequences of transnational educational mobility: a systematic literature review. Educational Research Review, 20, 81-98. https://doi.org/10.1016/j. edurev.2016.12.001.

Waibel, S., Petzold, K., \& Rüger, H. (2018). Occupational status benefits of studying abroad and the role of occupational specificity - a propensity score matching approach. Social Science Research, 74, 45-61. https://doi.org/10.1016/j.ssresearch.2018.05.006.

Waters, J. (2009). Transnational geographies of academic distinction: the role of social capital in the recognition and evaluation of 'overseas' credentials. Globalisation, Societies and Education, 7(2), 113-129. https:/doi. org/10.1080/14767720902907895.

White, I., Royston, P., \& Wood, A. (2011). Multiple imputation using chained equations: issues and guidance for practice. Statistics in Medicine, 30(4), 377-399. https://doi.org/10.1002/sim.4067.

Wiers-Jenssen, J. (2011). Background and employability of mobile vs. non-mobile students. Tertiary Education and Management, 17(2), 79-100. https://doi.org/10.1080/13583883.2011.562524.

Wiers-Jenssen, J., \& Try, S. (2005). Labour market outcomes of higher education undertaken abroad. Studies in Higher Education, 30(6), 681-705. https://doi.org/10.1080/03075070500340028.

Xie, Y., Brand, J., \& Jann, B. (2012). Estimating heterogeneous treatment effects with observational data. Sociological Methodology, 42(1), 314-347. https://doi.org/10.1177/0081175012452652.

Young, R., \& Johnson, D. (2010). Imputing the missing Y's: implications for survey producers and survey users. Proceedings of the AAPOR Conference, 2010, 6242-6248.

Zimmermann, J., \& Neyer, F. (2013). Do we become a different person when hitting the road? Personality development of sojourners. Journal of Personality and Social Psychology, 105(3), 515-530. https://oi. org/10.1037/a0033019.

Zimmermann, J., Greischel, H., \& Jonkmann, K. (2020). The development of multicultural effectiveness in international student mobility. Higher Education. https://doi.org/10.1007/s10734-020-00509-2.

Publisher's note Springer Nature remains neutral with regard to jurisdictional claims in published maps and institutional affiliations. 